\title{
METHODOLOGICAL PROVISION OF THE INDIVIDUAL RISK ASSESSMENT OF LUNG DISEASE ASSOCIATED WITH EXPOSURE TO DUST FACTOR OF WORKPLACE ON THE BASE PF EVOLUTIONARY MODELS
}

\author{
N.V. Zaitseva, V.B Aleksyeev, P.Z. Shur, D.A. Kiryanov, \\ D.M. Shlyapnikov, V.M. Chigvintsev
}

Federal Budget Scientific Institution "Federal Scientific Center for Medical and Preventive Health Risk Management Technologies", Russian Federation, Perm, 82 Monastyrskaya St., 614045

\begin{abstract}
As the development of semi-quantitative method for risk assessment of lung disease progression due to occupational exposure to the dust factor, the risk forecast method has been proposed, which bases on the evolutionary modeling. The proposed method has a number of advantages associated with variable working conditions of workers in relation to dust concentrations in the breathing zone and the intensity of the labor process. The proposed methodology allows performing calculations at various time steps, and consider the intervals between shifts and exit out of the exposure area, risk reduction during the holiday weekend, as well as for long periods of time (vacation, breaks in work). For use in the practice the simplified algorithm, which allows to perform risk assessment on the basis of special tabulations, has been suggested.
\end{abstract}

Key words: dust factor, occupational diseases, evolutionary modeling, risk assessment.

Occupational diseases associated with exposure to aerosols (pneumoconiosis and pneumosclerosis, chronic bronchitis), over the years, have ranked third in frequency of occupational diseases in Russia [4].

For a large group of aerosols (aerosols from the disintegration of coal, carbon-based sprays, aerosols coke (coal, sand, oil shale), blacks, diamonds, carbon fiber materials, aerosols (dust) animal and vegetable origin, silicate dust, silicates, aluminosilicates, aerosols from disintegration and condensation of the metal, silicon dust) that do not have pronounced toxicity, it is important to allocate the fibrogenic effect on human body.

(C) Zaitseva N.V., Aleksyeev V.B., Shur P.Z., Kiryanov D.A., Shlyapnikov D.M., Chigvintsev V.M., 2014

Zaitseva Nina Vladimirovna - Fellow of the Russian Academy of Medical Sciences, MD, Professor, Director (e -mail: znv@fcrisk.ru; phone:+7 (342) 237-25-34).

Alexeev Vadim Borisovich - PhD, DSc in Medicine, Deputy Director for organizational and methodological work (e-mail: vadim@fcrisk.ru; phone: +7 (342) 236-32-70).

Shur Pavel Zalmanovich - MD, Secretary of the Academic Council (e-mail: shur@fcrisk.ru; tel.: 8 (342) 238-33-37).

Kiryanov Dmitry Aleksandrovich - Head of Department of Systems and Processes Mathematical Modeling (e-mail: kda@fcrisk.ru; phone: +7 (342) 237-18-04).

Shlyapnikov Dmitry Mikhailovich - Head of The Health Risk Analysis Department (e-mail: shlyapnikov@fcrisk.ru; phone: +7 (342) 238-33-37).

Chigvintsev Vladimir Mikhailovich - Research assistant of department for mathematical modeling of systems and processes (e-mail: cvm@fcrisk.ru; phone: +7 (342) 237-18-04). 
Since the requirement to completely remove hazardous substances from the working area of workers is often not feasible, hygienic regulation of harmful substances and compliance with the maximum allowable concentration (MAC) of harmful substances in the air of the working area become particularly important. If the level of dust in the working area exceeds the maximum permissible concentration, workers can face a risk of occupational diseases related to exposure to aerosols. Such risk should be evaluated, and the results taken into account in the development of ongoing treatment, preventative and rehabilitation activities [1].

Exposure assessment is an integral part of quantitative risk assessment. A general way to assess occupational risk related to dust is assessment of the dust concentration and duration of its effect. In real working environment, monitoring of the PFA (predominantly fibrogenic aerosols) level in the working area takes into account the fluctuations of the PFA level during a working shift, as reflected in GOST R 54578-2011 Predominantly fibrogenic aerosols. According to GOST R 54578-2011, exceeding MPCas (average allowable concentration of dust in the working area per shift) calls for a calculation of the total dust load (DL) per employee, including variations in the actual average shift concentration in the working area during the contact with PFA. DL is a product of the actual average shift concentration in the working area, duration of professional contact with the PFA (years), the number of shifts worked in a calendar year under the impact of PFA, and pulmonary ventilation volume per shift (m3).

The current method involves comparing the obtained DL value with the control dust load (CDL) value, which is the product of the average allowable dust concentration in the working area per shift, duration of professional contact with the PFA (years), the number of shifts worked in a calendar year under the impact of PFA, and pulmonary ventilation volume per shift (m3). Results of the comparison of the actual dust load with the control dust load put the workplace either in an acceptable (safe) environment category or harmful environment category.

The method of semi-quantitative risk assessment indicated in GOST makes it possible to rank working environments which can later be used when developing medical and preventative programs. At the same time, evolutionary modelling is a more appropriate method when it comes to estimating individual professional risks, especially in conditions of variable factor exposure and longer breaks.

Description of the method. Individual professional risk of lung diseases associated with PFA exposure is assessed by calculating the index which takes into account the likelihood of disease and its severity as a characteristic of health damage. The calculation of risk is performed 


\section{Scientific and methodological approaches to risk analysis}

using the equation:

$$
R=P \cdot g,
$$

where $\mathrm{P}$ - is the probability of a professional disease; $\mathrm{g}$ - the coefficient of disease severity.

Disease severity is indicated with the values recommended by WHO (1994).

$-\mathrm{g}=0.4$ for pneumoconiosis;

$-\mathrm{g}=0.5$ for chronic respiratory diseases.

Calculation of the probability of a professional lung disease associated with lung exposure should be conducted based on the evolutionary model analysis [2, 3]. Evolutionary model is presented in the form of recurrent ratios allowing organizing an iterative computational procedure based on time intervals and reflecting the change in the probability of a disease associated with dust exposure.

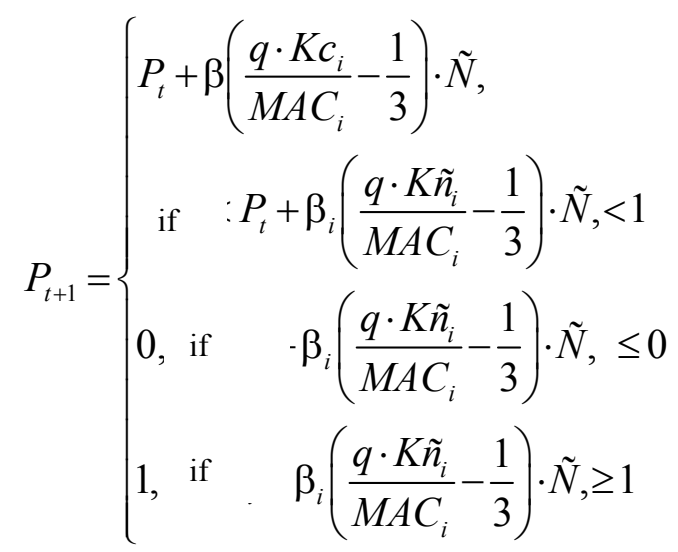

Where $P_{t+1}$ - is the probability of an occupational disease at a time interval $\mathrm{t}+1 ;{ }^{{ }_{t}}$ - probability of an occupational disease at a time interval $\mathrm{t} ; \beta$ - factor that characterizes the change in the probability of a disease associated with dust exposure depending on the fibrogene level. For dusts with a low fibrogene content $\beta=0,0021$, for dusts with a moderate/high fibrogene content $\beta=0,005 ; K c_{i}$ - average dust concentration of $i$ substance for the period of time that equals the time interval, in the workplace breathing area, $\mathrm{mg} / \mathrm{m} 3$; MAC - maximum allowable concentration of $\mathrm{i}$ substance in the workplace breathing area, $\mathrm{mg} / \mathrm{m} 3 ; \mathrm{q}$ - factor that depends on labor intensity and reflects a possible dose, proportional to the volume of lung ventilation per shift and taking the following values:

$-0,4$ for light work;

$-0,7$ for moderate work; 
-1 for heavy work.

$\mathrm{C}$ - time empirical factor that corresponds with the time interval as shown in Table 1.

Table 1

\section{$C$ factor value for the risk value calculation over the period $t$}

\begin{tabular}{|c|c|c|c|c|c|}
\hline \multirow{2}{*}{ Factor } & \multicolumn{5}{|c|}{ Time interval } \\
\cline { 2 - 6 } & Hour & Day & Week & Month & year \\
\hline C & 0,000114 & 0,00274 & 0,019231 & 0,083333 & 1 \\
\hline
\end{tabular}

A variation of the recurrent ratio (2) with the account for the complexity of dust content in the workplace breathing area that impacts the probability of occupational diseases can be presented in the following form:

$$
P_{t+1}=\left\{\begin{array}{l}
P_{t}+\beta\left(\sum_{i} \frac{q \cdot K \tilde{n}_{i}}{M A C_{i}}-\frac{1}{3}\right) \cdot \tilde{N} \\
\quad \text { if } \quad<P_{t}+\beta_{i}\left(\sum_{i} \frac{q \cdot K \tilde{n}_{i}}{M A C_{i}}-\frac{1}{3}\right) \cdot \tilde{N},<1 \\
\left(\begin{array}{rl}
\text { if } \quad & +\beta_{i}\left(\sum_{i} \frac{q \cdot K \tilde{n}_{i}}{M A C_{i}}-\frac{1}{3}\right) \cdot \tilde{N}, \leq 0 \\
1 & \text { if } \quad{ }_{t}+\beta_{i}\left(\sum_{i} \frac{q \cdot K c_{i}}{M A C_{i}}-\frac{1}{3}\right) \cdot \tilde{N}, \geq 1
\end{array}\right.
\end{array}\right.
$$

Ratio (2) піs used for the dusts of the same fibrogene level. In the event when a working area has dusts of various fibrogene levels, it is necessary to make calculations for each of the fibrogene levels.

Recurrent ratios (2), (3) allows for a consequent calculation of the value of disease probability at various time intervals beginning from the reference level. The reference level of the probability of occupation disease associated with a hazardous impact of the dust factor corresponds to a zero stage under PFA exposure and equals zero:

$$
\mathrm{P} 0=0 \text {. }
$$

On the basis of the ratio (2) or (3) and the reference level (4), it is then possible to make calculations at the subsequent time intervals: P1, P2, P3, P4, etc.

Selection of a time interval in the calculations that use recurrent ratios relations depends on the particularization of exposure. With permanent dust exposure during the entire period of work, the time interval equals one year. With variable exposure, the time interval must 
correspond to the period of cyclicity, i.e. in the presence of cycles of changes in the values of dust concentration of more than 1 month, 1 month interval is selected, for any changes in a week or a month - 1 day, for changes during a shift - 1 hour.

The average dust concentration per time interval (Kci) that corresponds with the time interval is calculated using the following equation:

$$
K c_{i}=\frac{\sum_{t=0}^{n} K_{t i}}{n}
$$

where Kti - dust concentration of $\mathrm{i}$ substance per $\mathrm{t}$ hour, $\mathrm{mg} / \mathrm{m} 3 ; n$ - hours in the time interval.

Calculation of the probability of occupational diseases under PFA exposure based on the recurrent ratios makes it possible to account for the irregular nature of dust exposure during a time interval. At the same time, it takes into account not only the level of exposure that can change during the shift, but also the duration of in-between shifts period.

The following scale is used in the assessment of occupational risk:

0-1·10-3 - low (moderate) risk (in guidance P 2.1.10.1920-04 - individual risk in the course of a lifetime more than $1 \cdot 10-4$, but less than $1 \cdot 10-3$ is indicated as acceptable for professional groups);

$1 \cdot 10-3-1 \cdot 10-2$ - average (significant) risk;

$1 \cdot 10-2-1 \cdot 10-1-$ high (intolerable) risk;

1 - very high (intolerable) risk.

Example. To demonstrate the practical application of the risk assessment method based on evolutionary models, we shall calculate the risk of chronic toxic bronchitis from vanadiumcontaining slag and dust among workers under permanent exposure to vanadium-containing dusts, for the three levels of average-shift concentration: $4 \mathrm{mg} / \mathrm{mg} 3,5.5 \mathrm{mg} / \mathrm{mg} 3,20 \mathrm{mg} / \mathrm{mg} 3$.

The value ПДК

The calculation included three possible exposure scenarios:

- first scenario $K c c=4 \mathrm{mg} / \mathrm{mg} 3$ (maximum allowable concentration);

- second scenario $K c c=5.5 \mathrm{mg} / \mathrm{mg} 3$ (slightly higher than the maximum allowable concentration);

- third scenario $K c c=20 \mathrm{mg} / \mathrm{mg} 3$ (5-fold higher than the exposure level). 
It is assumed that the calculation is made for the employment period beginning at the age of 20, with a high level of labor intensity $(q=1)$.

The value $K c c$ for each of the scenarios is considered constant during the entire employment period.

In this case, it is necessary to make calculations with the time interval of 1 year $(\mathrm{C}=1)$ for each of the scenarios. The average annual concentration can be calculated using the following formula:

$$
K c=\frac{K c c \cdot n_{1} \cdot n_{2}}{24 \cdot 365}
$$

when $\mathrm{n} 1$ - shift duration, hours;

$\mathrm{n} 2$ - number of shifts per year.

If $\mathrm{n} 1=8$ hours and $\mathrm{n} 2=251$ shifts, then $\mathrm{Kc}=\mathrm{Kcc} \cdot 0.23$. Then for the first scenario $\mathrm{Kc}=0.92$; for the second scenario $\mathrm{Kc}=1,265$; for the third scenario $\mathrm{Kc}=4.6$. The distribution of the average annual exposure in time is shown in Figure 1.

Vanadium-containing dusts are considered to be of low fibrogene content; that is why

$\beta=0.0021$. The probability of occupation disease is calculated based on the following formula:

$$
P_{t+1}=P_{t}+0,0021 \cdot\left(\frac{K c}{4}-\frac{1}{3}\right) \cdot 1
$$

Reference value $\mathrm{Pt}=20=0$.

Since the severity of chronic bronchitis $\mathrm{g}=0,5$, the risk of occupational disease is calculated based on the following formula:

$$
R=P_{t} \cdot 0,5 \text {. }
$$

The chronic bronchitis risk curve is shown in Figure 2. 


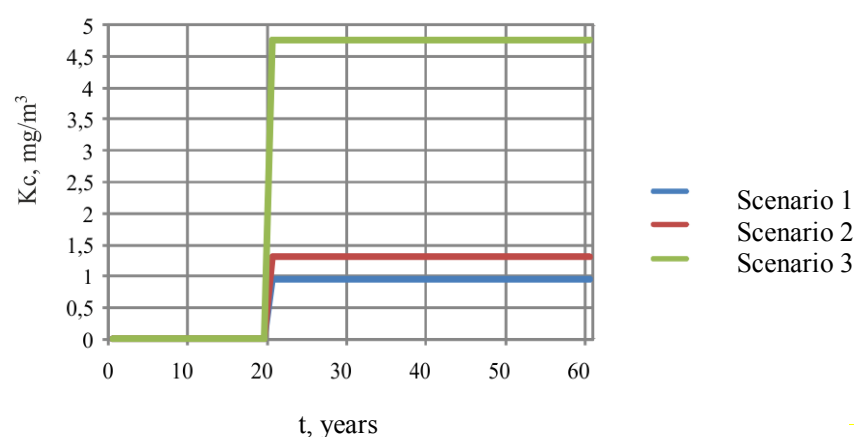

Fig. 1. Relationship between the average annual concentration of vanadium-containing slag and dusts in the working area and exposure time and level

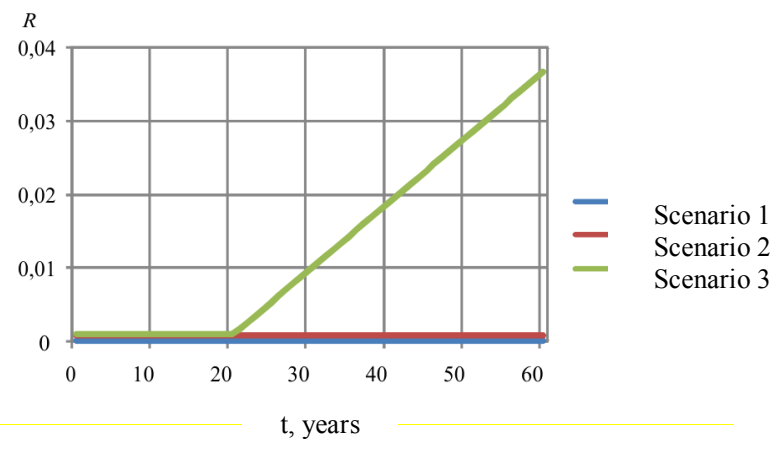

Fig. 2. Relationshıp between the chronic toxic bronchitis risk and the exposure time and level

Below are alternative calculations with shorter time intervals, to demonstrate the method.

The time interval of 1 day is characterized by changing exposure with a weekly cyclicity. In this case, in a standard workweek (Monday - Friday), the average daily concentration $\mathrm{Kc}=\mathrm{Kcc} \cdot 0.33$; on the weekend (Saturday - Sunday) $\mathrm{Kc}=0$. The graphic form of such exposure is shown in Figure 3. Here the risk dynamics takes the form of a polyline (Figure 4).

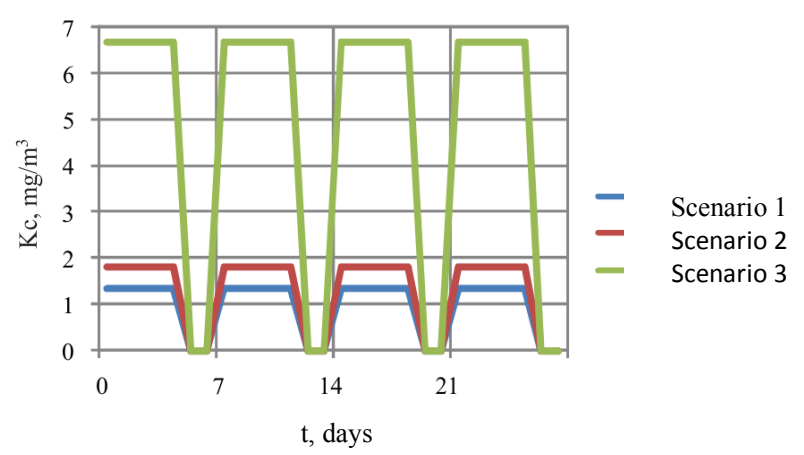

Fig. 3. Relationship between the average daily concentration of vanadium-containing slag and dust in bronchitis risk (daily averaging) and the exposure level the working area and the exposure time (daily averaging) and level

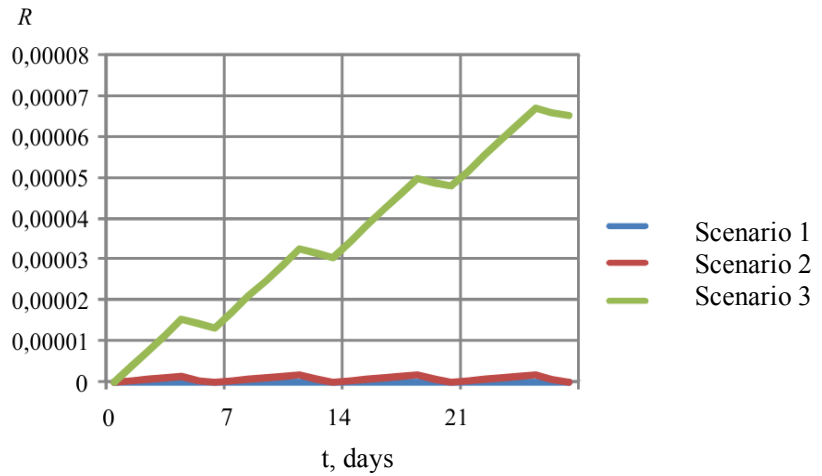

Fig. 4. Relationship between the chronic toxic

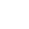

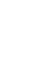




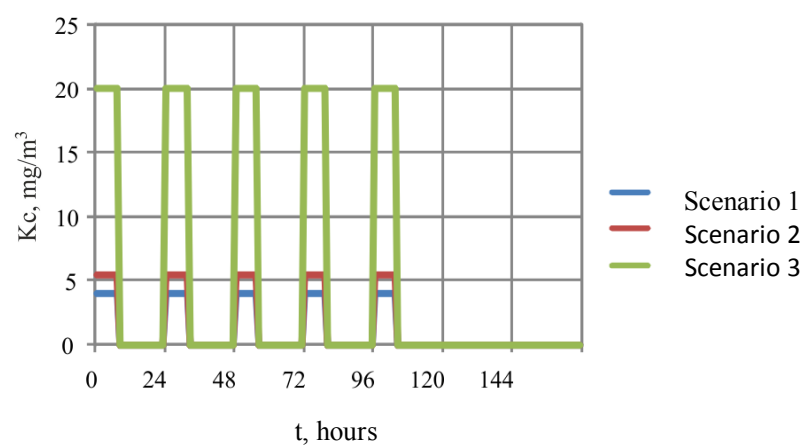

Fig. 5. Relationship between the average hourly concentration of vanadium-containing slag and dust in the working area and the exposure time (hourly averaging) and level

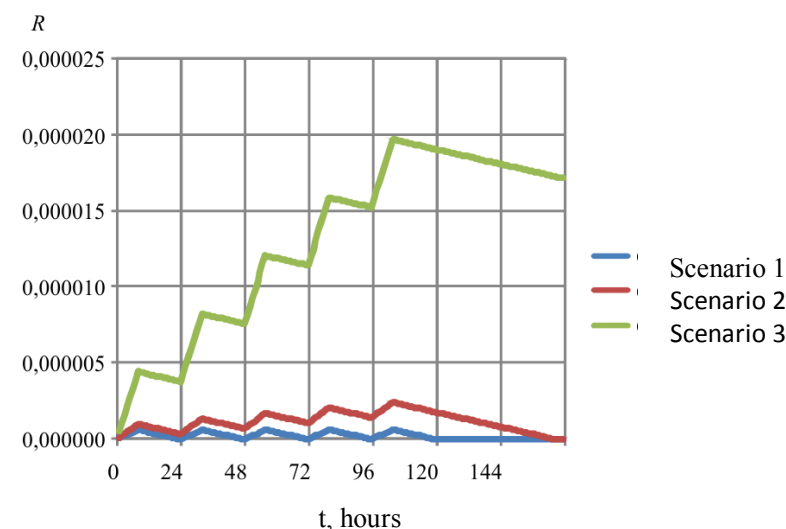

Fig. 6. Relationship between the chronic toxic bronchitis risk and the exposure time (hourly averaging) and level

Reduced calculation of the individual risk in workers. In the event of permanent dust exposure or long-term employment with permanent exposure, it is possible to calculate the individual risk of an occupational disease in workers using a reduced calculation method. This method uses canned tables that contain the values of the individual risk of a professional disease in workings depending on the employment period and exposure level as compared to MAC.

Step 1. Assess the exposure by determining the average annual relative dust load factor using the ratio:

$$
D L C=\frac{K c c}{M A C} \cdot \frac{n_{1}}{24} \cdot \frac{n_{2}}{365} \cdot q
$$

where DLC - average annual relative dust load coefficient; Kcc - average shift concentration; $\mathrm{n} 1$-shift duration, hours; $\mathrm{n} 2$ - number of shifts per year; $\mathrm{q}$ - quotient that depends on the work intensity and reflects a probably dose, proportionate to the volume of lung ventilation per shift and taken as:

$-0,4$ for light work;

$-0,7$ for moderate work;

-1 for heavy work.

Step 2. Based on the DLC value and the length of employment under permanent 
exposure, use Figures 7-10 to determine the value of the individual risk of a professional disease in workers. The disease risk value is at the intersection of the row that indicates employment, and column that shows the DLC (exposure).

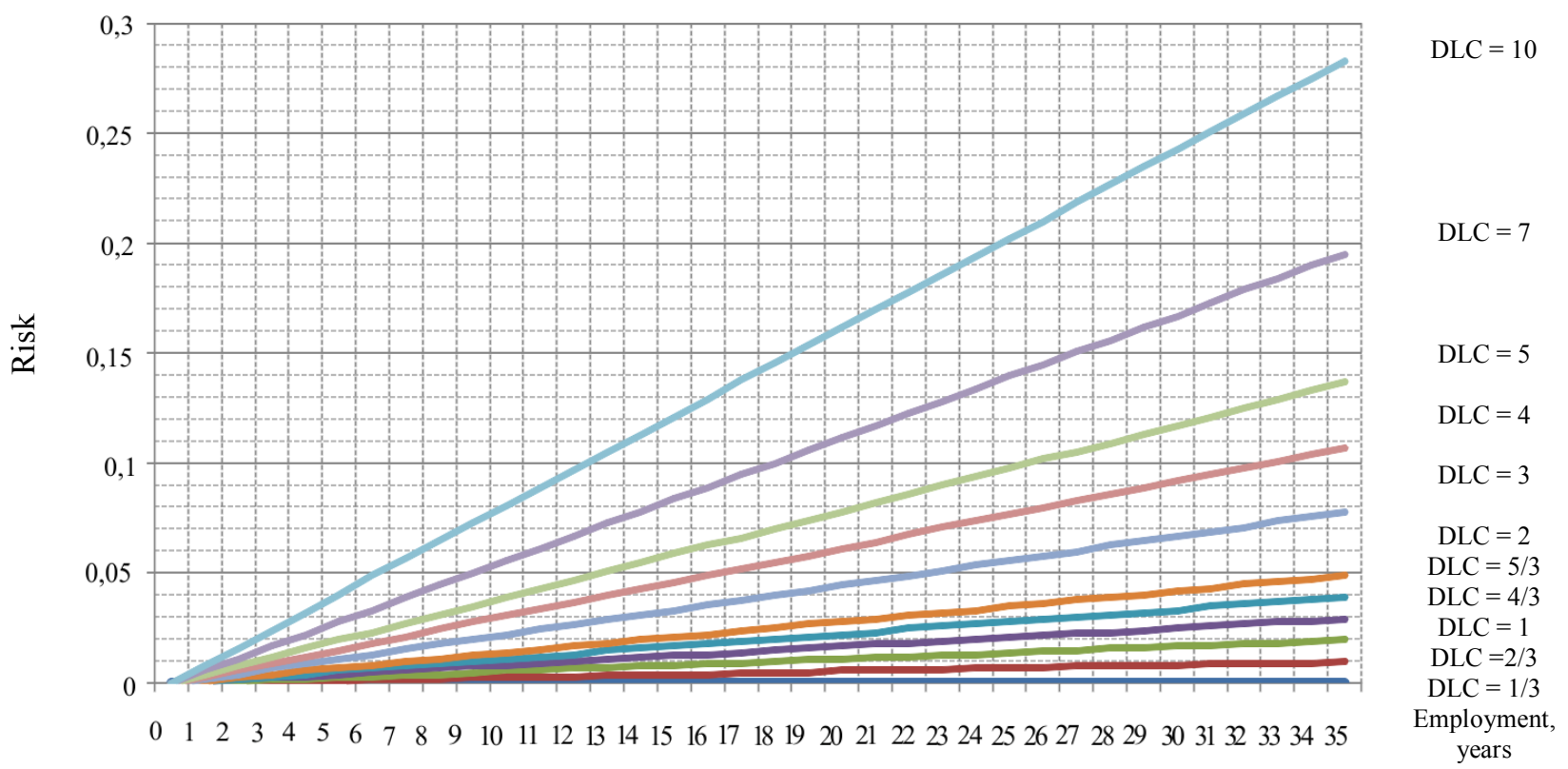

Fig. 7. Values of the individual disease risk as a function of time and exposure to PFA (dusts of low fibrogene content), disease severity equals 0.4

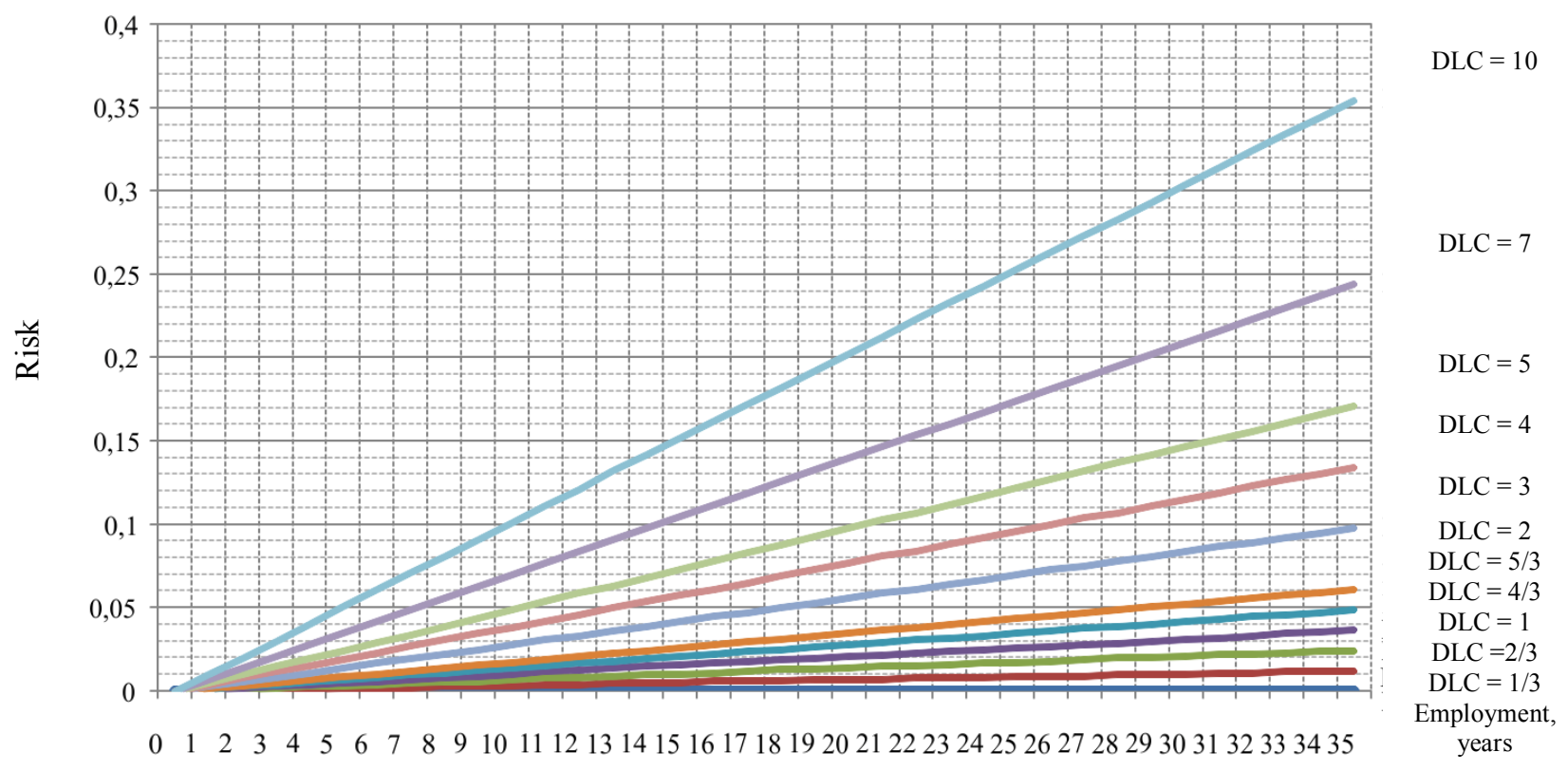

Fig. 8. Values of the individual disease risk as a function of time and exposure to PFA (dusts of low fibrogene content), disease severity equals 0 


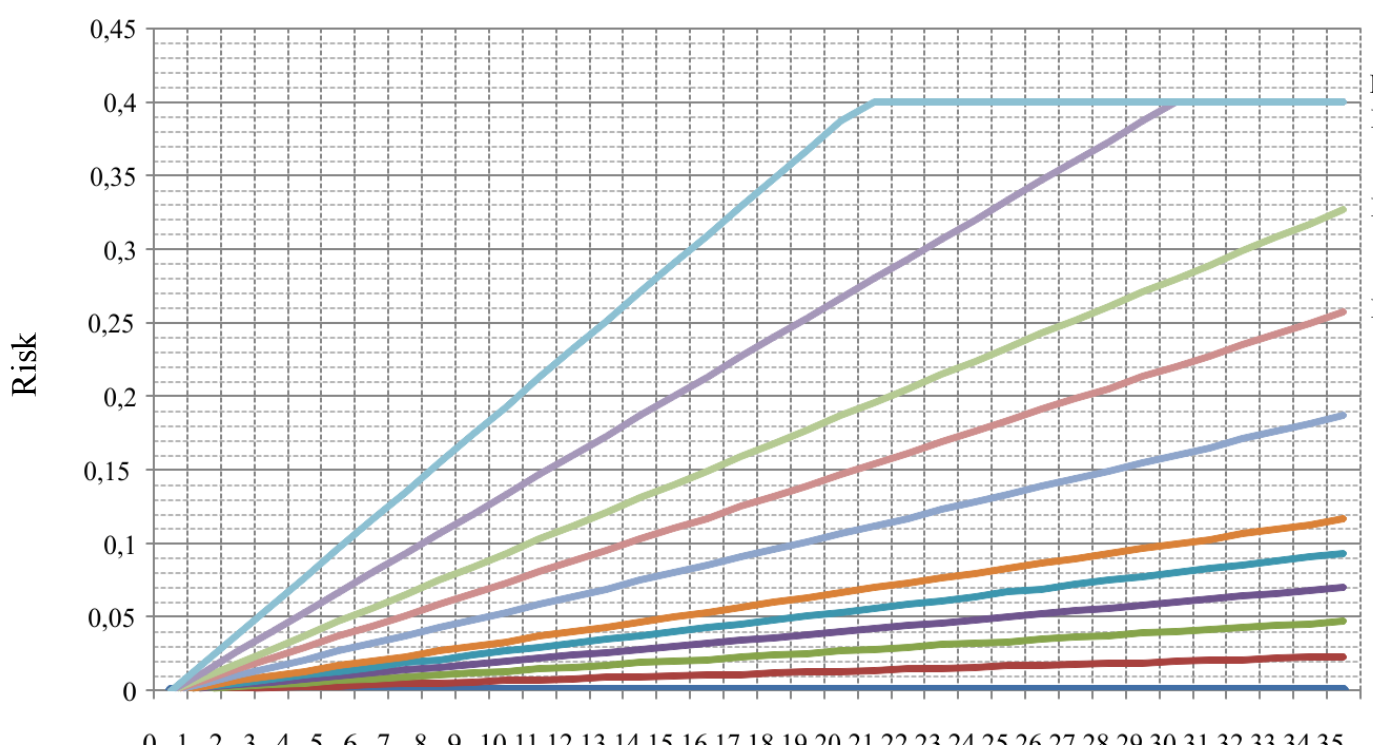

Fig. 9. Values of the individual disease risk as a function of time and exposure to PFA (dusts o

moderate fibrogene content), disease severity equals 0.4

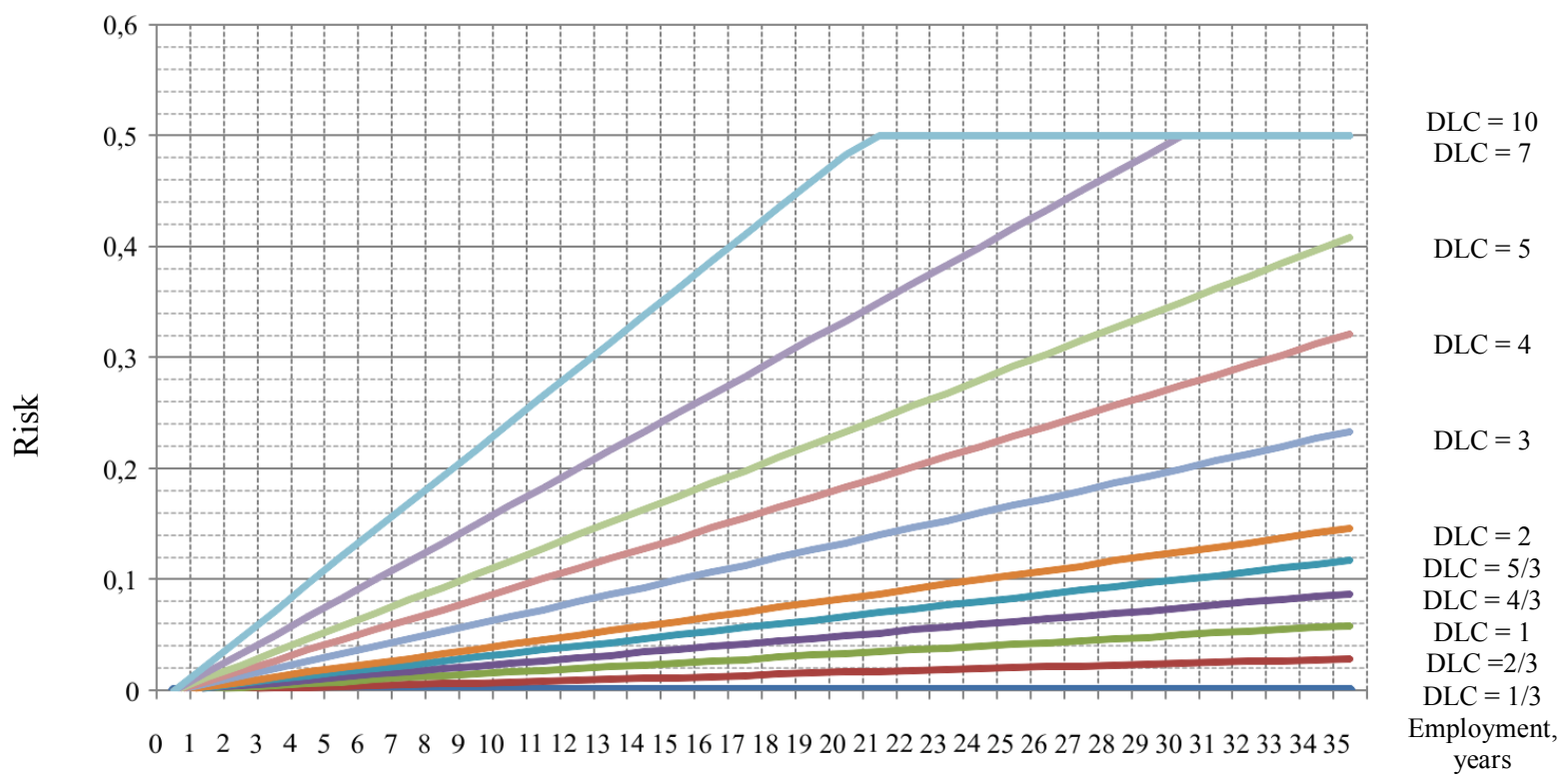

Fig. 10. Values of the individual disease risk as a function of time and exposure to PFA (dusts of high and

moderate fibrogene content), disease severity equals 0.5

If the calculated DLC is not found in the table, then the individual risk of a professional disease is calculated using the two adjacent for DLC probabilities according to the formula:
$\mathrm{DLC}=10$

$\mathrm{DLC}=7$

$\mathrm{DLC}=5$

$\mathrm{DLC}=4$

$\mathrm{DLC}=3$

$\mathrm{DLC}=2$

$\mathrm{DLC}=5 / 3$

$\mathrm{DLC}=4 / 3$

$\mathrm{DLC}=1$

DLC $=2 / 3$

DLC $=1 / 3$

Employment, years 


$$
R=R_{\dot{I}}+\left(\frac{D L C-D L C_{\dot{I}}}{D L C_{\hat{A}}-D L C_{\dot{I}}}\right) \cdot\left(R_{\hat{A}}-R_{\dot{I}}\right),(8)
$$

where DLC - average annual relative dust load coefficient; DLCL - lower value of DLC in the table; DLCH - higher value of DLC in the table; $R_{H}$ - individual risk of a professional disease that corresponds with the lower DLC value in the table (DLCL); $R_{B}$ - individual risk of a professional disease that corresponds with the higher DLC value in the table (DLCH)

Step 3. If the general employment period of a worker can be divided into intervals which vary by the level of dust exposure, then the individual risk of a professional disease shall be calculated as a sum of risks for the individual intervals:

$$
R=R^{1}+R^{2}+R^{3}+\ldots
$$

where $\mathrm{R} 1, \mathrm{R} 2, \mathrm{R} 3, \ldots-$ is an individual risk of a professional disease at various intervals of the employment period.

Step 4. If a worker has an extended break in the course of employment, then the accumulated individual risk of a professional disease can decrease. The value of decrease in the individual risk of a professional disease can be found in Table 2 in accordance with the necessary time interval.

Table 2

\section{Decrease in the individual risk of a professional disease due to a break in the work under

\begin{tabular}{|c|c|c|c|c|}
\hline \multirow{2}{*}{$\begin{array}{c}\text { Employ } \\
\text { ment, } \\
\text { years }\end{array}$} & \multicolumn{2}{|c|}{$\begin{array}{c}\text { Decrease in the probability of a disease } \\
\text { (severity } 0,4)\end{array}$} & \multicolumn{2}{|c|}{$\begin{array}{l}\text { Decrease in the probability of a disease } \\
\text { (severity } 0.5 \text { ) }\end{array}$} \\
\hline & $\begin{array}{c}\text { Dusts of low fibrogene } \\
\text { content }\end{array}$ & $\begin{array}{c}\text { Dusts of high/moderate } \\
\text { fibrogene content }\end{array}$ & $\begin{array}{l}\text { Dusts of low fibrogene } \\
\text { content }\end{array}$ & $\begin{array}{l}\text { Dusts of high/moderate } \\
\text { fibrogene content }\end{array}$ \\
\hline $1 / 12$ & $-0,00002$ & $-0,00006$ & $-0,00003$ & $-0,00007$ \\
\hline 1 & $-0,00028$ & $-0,00068$ & $-0,00035$ & $-0,00085$ \\
\hline 2 & $-0,00056$ & $-0,00132$ & $-0,0007$ & $-0,00165$ \\
\hline 3 & $-0,00084$ & $-0,002$ & $-0,00105$ & $-0,0025$ \\
\hline 4 & $-0,00112$ & $-0,00268$ & $-0,0014$ & $-0,00335$ \\
\hline 5 & $-0,0014$ & $-0,00332$ & $-0,00175$ & $-0,00415$ \\
\hline 6 & $-0,00168$ & $-0,004$ & $-0,0021$ & $-0,005$ \\
\hline 7 & $-0,00196$ & $-0,00468$ & $-0,00245$ & $-0,00585$ \\
\hline 8 & $-0,00224$ & $-0,00532$ & $-0,0028$ & $-0,00665$ \\
\hline 9 & $-0,00252$ & $-0,006$ & $-0,00315$ & $-0,0075$ \\
\hline 10 & $-0,0028$ & $-0,00668$ & $-0,0035$ & $-0,00835$ \\
\hline 11 & $-0,00308$ & $-0,00732$ & $-0,00385$ & $-0,00915$ \\
\hline 12 & $-0,00336$ & $-0,008$ & $-0,0042$ & $-0,01$ \\
\hline 13 & $-0,00364$ & $-0,00868$ & $-0,00455$ & $-0,01085$ \\
\hline 14 & $-0,00392$ & $-0,00932$ & $-0,0049$ & $-0,01165$ \\
\hline 15 & $-0,0042$ & $-0,01$ & $-0,00525$ & $-0,0125$ \\
\hline 16 & $-0,00448$ & $-0,01068$ & $-0,0056$ & $-0,01335$ \\
\hline 17 & $-0,00476$ & $-0,01132$ & $-0,00595$ & $-0,01415$ \\
\hline 18 & $-0,00504$ & $-0,012$ & $-0,0063$ & $-0,015$ \\
\hline
\end{tabular} dust expousre}




\begin{tabular}{|l|c|c|c|c|}
\hline 19 & $-0,00532$ & $-0,01268$ & $-0,00665$ & $-0,01585$ \\
\hline 20 & $-0,0056$ & $-0,01332$ & $-0,007$ & $-0,01665$ \\
\hline 21 & $-0,00588$ & $-0,014$ & $-0,00735$ & $-0,0175$ \\
\hline 22 & $-0,00616$ & $-0,01468$ & $-0,0077$ & $-0,01835$ \\
\hline 23 & $-0,0064$ & $-0,01532$ & $-0,008$ & $-0,01915$ \\
\hline 24 & $-0,00668$ & $-0,016$ & $-0,00835$ & $-0,02$ \\
\hline 25 & $-0,00696$ & $-0,01668$ & $-0,0087$ & $-0,02085$ \\
\hline 26 & $-0,00724$ & $-0,01732$ & $-0,00905$ & $-0,02165$ \\
\hline 27 & $-0,00752$ & $-0,018$ & $-0,0094$ & $-0,0225$ \\
\hline 28 & $-0,0078$ & $-0,01868$ & $-0,00975$ & $-0,02335$ \\
\hline 29 & $-0,00808$ & $-0,01932$ & $-0,0101$ & $-0,02415$ \\
\hline 30 & $-0,00836$ & $-0,02$ & $-0,01045$ & $-0,025$ \\
\hline
\end{tabular}

The reduced method of calculation of the individual risk serves for making an approximate assessment, and the calculation procedures are brought to a minimum. To use the reduced method effectively, most of the complicated calculations are put into canned tables that contain not only the risk values, but also the risk categories, according to the assessment scale; they are highlighted.

In summary, the method based on the drawing and analysis of the evolutionary models can be used widely in the field of professional disease detection and treatment. With the help of this method, it is possible to make assessment calculations not only for permanent dust exposure, but also for various distributions of exposure values during a shift, workweek, and year. Additionally, recurrent ratios used in risk assessment make it possible to conduct retrospective assessments and estimations that take into account an individual history of contact of a worker with the dust factor.

\section{References}

1. Zemljanova M.A., Zajceva N.V., Zvezdin V.N., Shljapnikov D.M. Vlijanie pylevoj nagruzki na pokazateli oksidantnoj i antioksidantnoj zashhity u rabotnikov staleplavil'nogo proizvodstva [Influence of dust load on the performance of oxidant and antioxidant protection in steelworks' employees]. Medicina truda i promyshlennaja jekologija, 2013, no. 11, pp. 17-21.

2. Trusov P.V., Zajceva N.V., Kir'janov D.A., Kamaltdinov M.R., Cinker M.Ju., Chigvincev V.M., Lanin D.V. Matematicheskaja model' jevoljucii funkcional'nyh narushenij v organizme cheloveka s uchetom vneshnesredovyh faktorov [Mathematical model of the evolution of functional disorders in the human body, taking into account environmental factors]. Matematicheskaja biologija $i$ bioinformatika, 2012, no. 2, pp. 589-610. Available at: http://www.matbio.org/2012/Trusov_7_589.pdf.

3. Zajceva N.V., Shur P.Z., Kir'janov D.A., Kamaltdinov M.R., Cinker M.Ju. Metodicheskie podhody $\mathrm{k}$ ocenke populjacionnogo riska zdorov'ju na osnove jevoljucionnyh modelej [Methodological approaches to the assessment of population health risk on the basis of evolutionary models]. Zdorov'e naselenija i sreda obitanija, 2013, no. 1(238), pp. 4-6.

4. Gosudarstvennyj doklad Rospotrebnadzora «O sostojanii sanitarnojepidemiologicheskogo blagopoluchija naselenija V Rossijskoj Federacii V 2011 godu» [Rospotrebnadzor State report "On the state sanitary and epidemiological welfare of the population in the Russian Federation in 2011"]. Moscow, 2012. 316 p. 